\title{
MIRIAM RONZONI Making Access to Trade Conditional on Labour Standards?
}

\author{
Christian Barry and Sanjay Reddy, International Trade and Labor \\ Standards: A Proposal for Linkage, New York, \\ Columbia University Press, 2008
}

Could the current global economic order be reformed in a way that would make it more defensible from a moral point of view? The book answers this question positively and makes one such proposal. In particular, it addresses the issue of how the protection of minimally adequate labour standards ${ }^{1}$ in developing countries could be guaranteed. The authors argue that a virtuous circle on this matter could be triggered by making every country's access to international trade conditional on the protection of labour standards. Thus, they advocate the implementation of a linkage scheme between labour standards and trade - a proposal that has been suggested before in WTO negotiations and in relevant scholarship, but that has been faced with fierce opposition and criticism both in those negotiations (mainly by developing countries) and in academia, interestingly by neoliberal and progressive scholars alike. Thus, the book is a refreshingly controversial contribution, and all the more so because it is the joint enterprise of a normative political philosopher and an international development economist. Thus, the proposal has the ambition of being both an ethical improvement of the status quo and a feasible option.

The book offers a preliminary account of linkage, its rationale and its problems (chapters 1, 2, and 3); a taxonomy of the main existing objections against linkage proposals of all kinds (chapter 4); a set of preliminary moral requirements that all linkage proposals must meet in order to be prima facie plausible (chapter 5); a systematic engagement with the 5 objections to linkage fleshed out in chapter 4, which partly refutes these objections, and partly accommodates them by formulating additional conditions that a defensible linkage proposal must meet (chapter 6); and finally, the sketch of a possible linkage system (chapter 7). The volume is then complemented by two extremely interesting sets of additional material: an appendix offering empirical evidence on the likely positive effects of improvements in labour standards (pp. 89-99), and a series of commentaries to the proposal by Kyle Bagwell, Rohini Hensman, Robert E. Goodin, and Roberto Mangabeira Unger, followed by a response by the authors. The idea to complement a book that makes a case for a policy proposal with a set of commentaries by experts of various fields is a particularly interesting and valuable choice. The commentaries and the response shed light on a variety of problems (normative,

1. The authors deliberately restrict their linkage proposal to a threshold of minimally adequate labour standards. Recommending the adoption of mechanisms of linkage to regulate the improvement of labour standards beyond such minimal threshold would go against the respect for cultural diversity that they explicitly commit to (pp. 61-67). 
political or economic) according to the expertise of the commentators. My only minor complaint about this part of the book is that the vast majority of the commentators have issues to raise, but are generally sympathetic to the revision of traditional linkage proposals made by the authors. The presence of more radically critical contributions, and responses to those critiques, would have made this part of the volume even more interesting.

As mentioned above, the idea of a labour-trade linkage is rather unpopular in political, activist and academic circles. The most widely shared reason why a linkage scheme should not be implemented is that it is ultimately yet another protectionist measure on the part of developed countries: labour standards will only provide an acceptable excuse to keep or even raise trade barriers with developing countries in those sectors where these are most competitive. Barry and Reddy, however, do not restrict themselves to this issue and identify 5 categories of objections that linkage proposals must face. These are systematically laid out in chapter 4 and then dealt with in detail in chapter 6; indeed, these two chapters are sufficiently independent from the rest of the book to constitute a good freestanding introduction to Barry's and Reddy's argument. The five sets of objections are, respectively: 1 . that linkage is self-defeating and counterproductive; 2. that there are better ways of promoting the same goals; 3 . that it creates an unfair distribution of burdens; 4 . that it is context blind and imperialistic; and 5 . that it is infeasible. For reasons of space, I will only focus on 1 , which is the set of objections to which Barry and Reddy respond by highlighting the most original feature of their proposal. It should be mentioned, however, that the authors concede that some of the objections which I shall not discuss offer good reasons to specify the contours of their linkage proposal with both more caution and more precision. For instance, they concede to the proponents of 4 that an adequate linkage system must be context-sensitive in its application and ensure that appropriate account is taken of viewpoints within states.

The first and most important set of objections that Barry and Reddy address is, then, that linkage is ultimately dangerous and counterproductive. This includes the aforementioned objections that linkage will provide an excuse for protectionism; that it will increase production costs in developing countries thus making their goods less competitive; that it will only affect export-producing sectors and thus be ultimately of rather limited reach; that it will create unemployment and drive bad practices "out of sight rather than out of existence" (p.13). Barry and Reddy respond to this set of problems by making a simple but illuminating point. Most discussions on linkage take for granted that it will work by imposing sanctions on countries who fail to implement minimally adequate labour standards effectively. The potentially counterproductive effects of linkage, however, loose much of their bite if this is understood in terms of a carrot, rather than stick, approach. For a system of linkage can operate by offering to developing countries that improve their labour standards additional benefits to those that are already currently guaranteed under the WTO system (pp. 32-33). In other words, a linkage mechanism may well be based on a system of incentives for good practices, rather than sanctions for bad practices. 
First of all, and for self-evident reasons, such a system would rule out the manipulation of the linkage scheme by affluent countries in protectionist directions. More broadly, the authors contend that this would create a virtuous circle of incentives for developing countries, rather than submitting them to a system of pressure through sanctions which might indeed do more harm than good. The additional production costs would be (at least) offset by the increased access to foreign markets through, inter alia, even lower tariffs than those already granted by the current WTO system. This, in turn, would seriously diminish both the risk of unemployment and the incentive for developing countries to carry on engaging in bad practices out of sight. Finally, it is worth adding that most of the points made by Barry and Reddy to defend linkage against the first set of objections (1) also provide them with good ex ante responses to the third (3). If linkage is structured around a system of incentives, rather than sanctions, then the challenge that it will create an unfair burden for the least advantaged becomes much weaker.

The gestaltic change made by suggesting a linkage system that operates through incentives rather than sanctions is an extremely illuminating one. Moreover, Barry and Reddy support their proposal by providing a detailed account of the difference this would make in terms of North-South relationships, fair allocation of burdens for the improvement of labour standards, and feasibility. The idea of an incentive-based linkage system is very promising, and its advocates have done a remarkable work in terms of highlighting its potential positive effects and its capacity to overcome the pitfalls of more traditional linkage proposals. However, like all innovative and ambitious proposals, Barry's and Reddy's will have to overcome several waves of challenges before its workability can be fully established. An incentive-based linkage system can address the flaws of sanctionbased ones, but does it not create its own, new problems? This is a question that must be addressed, and a debate that will most probably be triggered by Barry's and Reddy's contribution. Indeed, the development of such debate would be a proof of the challenging quality of their proposal.

In particular, I shall sketch, in a critical but constructive spirit, two areas of problems where I find Barry's and Reddy's proposal to need further work and elucidation. Firstly, the authors make a plausible case that some key features of their linkage mechanism with respect to previous proposals make it ethically superior to them, but it may well be the case that these very features also make it less appealing to affluent and powerful countries, and thus potentially less feasible. One of the main arguments of the book is that labour standards raise the same kind of collective action problem as tariff barriers did before the introduction of GATT. Defending one's competitiveness in the global market by lowering labour standards is in principle not different from raising trade barriers. In both cases, it would be better for all not to engage in the relevant practice, but it is too costly - indeed, borderline suicidal - for each country to stop the practice in isolation; only a collective agreement can tackle the issue successfully. Realizing this point with respect to trade barriers gave rise to GATT and subsequently to the WTO system. A similar collective solution might prove the only way to address labour 
standards. The main issue here, however, is whether a system of linkage like the one proposed by Barry and Reddy would constitute one such solution. It is true that in principle both developed and developing countries have an interest in labour standards in poor countries being improved. Developing countries have an interest in it because this would improve the lot of their own citizens, and developed countries can benefit from the likely increase in production costs and therefore decrease in competitiveness - of goods produced by developing countries as a result of the improved labour conditions. However, a truly incentive-based linkage would not make goods produced in developing countries less competitive - indeed, that is precisely what is meant to make it so morally attractive. If the system has to offer incentives to improve labour conditions, then the reward that complying countries would get in terms of easier access to foreign markets (probably via lower tariffs) has to be higher than the prima facie loss in competitiveness caused by raising production costs. The incentive works only if complying countries can gain the prospect of becoming even more competitive by improving their labour standards. If this is the case, however, it is not fully clear that affluent and powerful countries can be persuaded to accept the mechanism. Since the proposal means at being both morally attractive and feasible, this issue is worth pondering on.

Secondly, more work needs to be done to prove that an incentive-based system will ultimately work differently from a sanction-based one. Indeed, what needs to be proven is that a pure incentive-based system is possible at all when it comes to trade, where by "pure" I mean a system which only generates rewards for those who respond to the incentive and no disadvantages for those who do not. ${ }^{2}$ Trade being largely (although not exclusively) an issue of comparative advantage, privileged access to foreign markets for countries who improve their labour standards inevitably means loss of competitiveness for countries who do not. If country A's goods become cheaper in country B's market due to lower tariffs (which more than offset the higher production costs), then country C's goods which remain as expensive as country A's old prices but more expensive then A's new ones - inevitably loose competitiveness. A natural response to this objection may be that country $\mathrm{C}$ can also improve its labour standards and get preferential access to country B's market. If this is the logic, however, the scenario is no longer different from that of a sanction-based system. Countries which suffer sanctions due to their failure to improve labour stands also have the option of improving them and being relieved from the sanctions. What we worry about in these cases, however, is that not all countries will or will be able to do so, or will do it quickly enough, and in the meantime those who will suffer most will be the worst off. Let me try and flesh out this point more clearly. In a case like trade, better access to some markets for some means, other things being equal, worse access for

2. Admittedly, responding to Kyle Bagwell's commentary, the authors claim that theirs is not a pure "carrot" system (pp. 141-143): a system of incentives can offer rewards for compliance and disadvantages for lack of compliance at the same time. However, the authors do not consider the specific issue of how the compliance of some countries will affect the comparative position of other countries, and how this consideration might make the difference between a system of negative and one of positive sanctions less stark. 
others - that is, rewards for some mean sanctions for others. If this is the case, however, the poor in countries who do not improve their labour standards might suffer just as much under an incentive-based system as under a sanction-based system. Moreover, what needs to be noted is that, in both scenarios, the poorest countries are the most likely to fall into the trap. Improving labour standards creates an immediate cost, which can then be offset by having better access to foreign markets. The reward is, however, not immediate - the improved labour standards have to be effectively implemented first and compliance with them has to be adequately checked - and the costs in the meantime might be high, especially if other countries have already gained privileged access to trade in the meantime. In such a scenario, extremely poor countries might get into a trap where they lack the economic and political resources to incur the immediate costs in light of the long-term benefits, and might even be forced to further worsen labour standards to regain some competitiveness in the short run. Thus, unless some details of the proposal are further clarified, its effect might be to further widen the gap between middle income countries and emerging economies (Like China, Mexico, Malaysia, Brazil or India among others) on the one hand and severely poor countries (mainly African) on the other. This need not be an inevitable scenario, but one whose empirical likelihood needs to be studied in more detail.

The two challenges raised above are serious, but need not be devastating. Indeed, the motivation behind raising them is very much in the same spirit as Barry's and Reddy's extremely challenging proposal - namely, elaborating and testing reform proposals for the global economic order that can be both feasible and morally justifiable. More interdisciplinary work will be needed to understand whether Barry's and Reddy's proposal can actually meet the test. But the book is definitely, and deservingly, destined to provoke intense and animated debate. 